\title{
Thermal decomposition and flammability of rigid PU foams containing some DOPO derivatives and other phosphorus compounds
}

\author{
Xiu Liu ${ }^{\text {a, b }}$, Khalifah A. Salmeia ${ }^{b}$, Daniel Rentsch ${ }^{c}$, Jianwei Hao** a , Sabyasachi Gaan* ${ }^{\text {b }}$ \\ ${ }^{a}$ National Laboratory of Flame Retardant Materials, National Engineering and Technology Research Center of Flame Retardant Materials, \\ School of Materials Science and Engineering, Beijing Institute of Technology, Beijing 100081, China. \\ ${ }^{b}$ Additives and Chemistry Group, Advanced Fibers, Empa, Swiss Federal Laboratories for Materials Science and Technology, Lerchen- \\ feldstrasse 5, 9014 St. Gallen, Switzerland. \\ ${ }^{C}$ Laboratory for Functional Polymers, Empa, Swiss Federal Laboratories for Materials Science and Technology, Überlandstrasse 129,8600 \\ Dübendorf, Switzerland
}

\begin{abstract}
A series of 9, 10-dihydro-9-oxa-10-phosphaphenanthrene-10-oxide (DOPO) based derivatives were synthesized and incorporated as flame retardant additives in rigid polyurethane foam (RPUF). The flame retardant performance of DOPO derivatives in RPUF was investigated and compared with traditional flame retardant tris(1-chloro-2-propyl) phosphate (TCPP) and reactive flame retardant (diol) based on oligomeric ethyl ethylene phosphate (PLF140). The flame retardant performance of rigid foams was evaluated by UL 94 HB test, limiting oxygen index (LOI) and cone calorimetry (CONE). Thermal stability of RPUF samples was analyzed by thermogravimetric analysis (TGA) and pyrolysis combustion flow calorimeter (PCFC). The thermal decomposition mechanism of the flame retardant RPUF and the mode of action of the flame retardants were investigated via pyrolysis-gas chromatography-mass spectrometry (Py-GC-MS) and thermogravimetric analyzer coupled with FTIR and MS (TG-FTIR-MS). Scanning electron microscope-energy dispersive X-ray (SEMEDX) was used to analyze the char residue of the RPUF. It was observed that, addition of $2 \mathrm{wt} \%$ phosphorus in RPUF helps achieve HF1 rating in UL 94 HB test and reduces the peak of heat release rate by $23 \%-42 \%$ in cone calorimeter measurements. Additionally, in cone calorimeter measurements, compared to RPUF containing TCPP and PLF140, RPUF containing DOPO derivatives exhibit lower smoke and toxicant production and increased char residue. For RPUF containing 6-(2-(4,6-diamino1,3,5-triazin-2-yl)ethyl) dibenzo[c,e][1,2]oxaphosphinine 6-oxide (DTE-DOPO), production of decomposition products such as -NCO containing compounds, HCN, hydrocarbons, amines and cyanic acid were significantly decreased compared to virgin RPUF. RPUF/DTE-DOPO formulation resulted in a compact and tough char structure which proves its strong barrier effect in the condensed phase. The detailed flame retardant mechanisms of TCPP and DTE-DOPO in RPUF are further elaborated in this work.
\end{abstract}

\section{Introduction}

Increasing demand for environmental protection has put more emphasis on energy conservation. Rigid polyurethane foam (RPUF) as an insulation material is used in many fields of applications, especially in buildings, due to its superior physical and mechanical properties and

\footnotetext{
* Corresponding author

E-mail addresses: sabyasachi.gaan@empa.ch (S. Gaan)

** Corresponding author

E-mail addresses: hjw@bit.edu.cn (J.W.Hao)
} 
low thermal conductivity \{between 0.018 and $0.028 \mathrm{~W} /(\mathrm{m} \mathrm{K})$ \} [1,2]. However, the RPUF which has a closed cell structure is highly flammable and its flame spread is quite fast in case of a fire [3-5]. With the wide applications of RPUF as an insulation material, more and more building fires are caused by the RPUF, resulting in great loss of life and economic risk [6]. The application of RPUF is limited in the construction industry due to the strict requirements on the flame retardancy required by some regulations such as Final Draft prEN 13501-1 [7,8]. To improve the flame resistance of RPUF, various types of flame retardants based on halogen, phosphorus, nitrogen, etc. have been used. TCPP is one of the most popular flame retardants used in RPUF because it is economical and efficient $[9,10]$. However, the use of halogencontaining flame retardants is restricted in some applications because of their toxicity $[11,12]$. The use of TCPP results in an increase in the smoke toxicity of polyurethane as large amount of toxic and corrosive gases such as $\mathrm{CO}$ and $\mathrm{HCl}$ are released during the combustion process $[10,13]$, which are not conducive to evacuation and rescue operations. To substitute the halogenated flame retardants, development of new and efficient environment friendly halogen-free flame retardants are needed.

DOPO compound and its derivatives are found to be efficient as flame retardants and have attracted a lot of attentions in recent years [14,15]. Owing to the aromatic structures, they have higher thermal and chemical stability compared to other linear low molecular weight aliphatic phosphinates [16,17]. Derivatives of DOPO are not only active in the gas phase but also in the condensed phase with a high char-forming ability. They have been shown to release low molecular weight phosphorous containing species which are able to scavenge the $\mathrm{H}$ and $\mathrm{OH}$ radical species in the fire $[18,19]$. The low toxicity and high efficiency of some DOPO based derivatives makes them suitable candidates for the replacement of toxic halogen-containing flame retardants in polyurethane foams [20]. As effective flame retardants, DOPO derivatives are used in epoxy resins [14,21,22], flexible polyurethane foams [9,19,23] and rigid polyurethane foams [24]. However, there are limited reports on the usage of DOPO derivatives as flame retardants and smoke suppressants in rigid PU foams.

In this work, DOPO-based derivatives 6-(2-(6-oxido-6H-dibenzo[c,e][1,2] oxaphosphinin-6yl)amino)ethoxy)-6H-dibenzo[c,e][1,2] oxaphosphinine 6-oxide (ETA-DOPO), 6-(2-(4,6diamino-1,3,5-triazin-2-yl)ethyl) dibenzo[c,e][1,2]oxaphosphinine 6-oxide (DTE-DOPO) and 3-(6-oxidodibenzo[c,e][1,2]oxaphosphinin-6-yl)propanamide (AAM-DOPO) were synthesized and incorporated in the RPUF. Subsequently the flame retardant properties of DOPO based derivatives were compared with TCPP and a reactive (diol) oligomeric ethyl ethylene phosphate (PLF140) based flame retardant. The flame-retardant and thermal degradation performance of RPUF was analyzed using CONE, LOI and PCFC. The mode of thermal decomposition of RPUF and mode of action of different flame retardants are further elaborated in this work. 


\section{Experimental}

\subsection{Materials and Methods}

Polyol (VORANOL ${ }^{\mathrm{TM}}$, hydroxyl value, $345-375 \mathrm{mg} \mathrm{KOH} / \mathrm{g}$; viscosity at $25^{\circ} \mathrm{C}$, 2500-3500 $\mathrm{mPa}$ ), Polyol (VORANOL ${ }^{\mathrm{TM}}$, hydroxyl value, 400-425 mg KOH/g; viscosity at $25^{\circ} \mathrm{C}$, 4700$5900 \mathrm{mPa}$ s). MDI (VORANATETM M 600 Polymeric MDI-ISOCYANATES, NCO \%, 30.0-31.4; viscosity at $25^{\circ} \mathrm{C}, 500 \mathrm{mPa} \mathrm{s}$ ), dibutyltindilaurate, triethylene diamine, silicone surfactant Tegostab 8460 and blowing agent cyclopentane were kindly supplied by Dow Chemical Europe SA. TCPP and PLF140 was kindly supplied by Fritz Nauer AG, Switzerland. from Thor $\mathrm{GmbH}$, Germany respectively. All other chemicals were purchased from Sigma-Aldrich and used as received without any further purification. ETA-DOPO and DTEDOPO were prepared as previously published [20,25,26].

\subsection{Synthesis of AAM-DOPO}

A dry four neck reactor connected to mechanical stirrer, $\mathrm{N}_{2}$ inlet, thermometer and a condensor was charged with acrylamide (149.97 g, $2.11 \mathrm{~mol})$, DBU (64.24 g, $0.42 \mathrm{~mol})$ and Toluene (3L). The mixture was then heated up to $80{ }^{\circ} \mathrm{C}$. The temperature was then decreased to $60{ }^{\circ} \mathrm{C}$ and DOPO (478. $59 \mathrm{~g}, 2.2 \mathrm{~mol})$ was added in small portions at a rate that the temperature of the mixture did not exceed $90{ }^{\circ} \mathrm{C}$. After complete addition, the mixture was stirred at $80{ }^{\circ} \mathrm{C}$ for $30 \mathrm{~min}$ and then refluxed for $6 \mathrm{~h}$. The reaction mixture was allowed to cool down to ambient temperature and the precipitated was then collected by filtration and stirred in ethanol for $1 \mathrm{~h}$. After filtration, the white solid was washed with water and dried in vacuum at $80{ }^{\circ} \mathrm{C}$. Yield: 75\%. m.p. $170{ }^{\circ} \mathrm{C}$. ${ }^{1} \mathrm{H}$ NMR (400.2 MHz, DMSO-d $6, J(H, H)$ and $J(H, P)$ are reported in $\left.\mathrm{Hz}\right) \delta$ (ppm): $8.21(\mathrm{ddd}, J=8.1,0.9, J(H, P)=4.8,1 \mathrm{H}, \mathrm{H}-5) ; 8.17(\mathrm{dd}, J=8.0,1.6,1 \mathrm{H}, \mathrm{H}-8) ; 7.93$ $(\mathrm{ddd}, J=7.7,1.1, J(H, P)=12.9,1 \mathrm{H}, \mathrm{H}-2) ; 7.79$ (m, 1H, H-4); 7.60 (dddd, $J=8.2,7.7,0.9$, $J(H, P)=3.1,1 \mathrm{H}, \mathrm{H}-3) ; 7.46(\mathrm{md}, J(H, P)=1.1,1 \mathrm{H}, \mathrm{H}-10) ; 7.36(\mathrm{~s}(\mathrm{br}), 1 \mathrm{H}, \mathrm{NHa}) ; 7.32$ (ddd, $J=8.1,8.0,1.3,1 \mathrm{H}, \mathrm{H}-9) ; 7.28$ (dd, $J=8.1,1.3,1 \mathrm{H}, \mathrm{H}-11) ; 6.89$ (s(br), 1H, NHb); 2.33-2.43 (m(br), 2H, H-13); 2.21-2.33 (m(br), 2H, H-14). For ${ }^{13} \mathrm{C}$ NMR data multiplicities $s=$ quaternary carbon, $d=\mathrm{CH}, t=\mathrm{CH}_{2}$, and $q=\mathrm{CH}_{3}$ are shown and ${ }^{31} \mathrm{P},{ }^{13} \mathrm{C}$ coupling constants are reported in Hz. ${ }^{13} \mathrm{C}$ NMR (100.6 MHz, DMSO-d $\left.{ }_{6}\right) \delta(\mathrm{ppm}): 171.9(\mathrm{sd}, J(C, P)=16.1, \mathrm{C}-15)$; $148.5(\mathrm{sd}, J(C, P)=8.2, \mathrm{C}-12) ; 134.5(\mathrm{sd}, J(C, P)=5.3, \mathrm{C}-6) ; 133.4(\mathrm{dd}, J(C, P)=2.0, \mathrm{C}-4)$; $130.8(\mathrm{~d}, \mathrm{C}-10) ; 129.7(\mathrm{dd}, J(C, P)=12.1, \mathrm{C}-2) ; 128.7(\mathrm{dd}, J(C, P)=13.3, \mathrm{C}-3) ; 125.7(\mathrm{~d}, \mathrm{C}-8)$; $124.8(\mathrm{~d}, \mathrm{C}-9) ; 124.4(\mathrm{sd}, J(C, P)=118.8, \mathrm{C}-1) ; 124.4(\mathrm{dd}, J(C, P)=8.9, \mathrm{C}-5) ; 121.9(\mathrm{sd}$, $J(C, P)=10.8, \mathrm{C}-7) ; 120.1(\mathrm{dd}, J(C, P)=5.4, \mathrm{C}-11) ; 27.2(\mathrm{td}, J(C, P)=3.4, \mathrm{C}-14) ; 23.1(\mathrm{td}$, $J(C, P)=99.3, \mathrm{C}-13) . \mathrm{HMBC}: \mathrm{H}-2 \rightarrow \mathrm{C}-(1 \mathrm{w}, 4,6) ; \mathrm{H}-3 \rightarrow \mathrm{C}-(1,5) ; \mathrm{H}-4 \rightarrow \mathrm{C}-(2,6) ; \mathrm{H}-5 \rightarrow$ $\mathrm{C}-(1,3,7) ; \mathrm{H}-8 \rightarrow \mathrm{C}-(6,10,12) ; \mathrm{H}-9 \rightarrow \mathrm{C}-(7,11) ; \mathrm{H}-10 \rightarrow \mathrm{C}-(8,12) ; \mathrm{H}-11 \rightarrow \mathrm{C}-(7,9) ; \mathrm{H}-13$ $\rightarrow \mathrm{C}-(14,15) ; \mathrm{H}-14 \rightarrow \mathrm{C}-(13,15) ; \mathrm{NHb} \rightarrow \mathrm{C}-(14)$. DQF-COSY: H-2 $\rightarrow \mathrm{H}-(3) ; \mathrm{H}-3 \rightarrow \mathrm{H}-(2$, 4); H-4 $\rightarrow$ H-(3, 5); H-5 $\rightarrow$ H-(4); H-8 $\rightarrow$ H-(9); H-9 $\rightarrow$ H-(8, 10); H-10 $\rightarrow$ H-(9, 11); H-11 $\rightarrow \mathrm{H}-(10) ; \mathrm{H}-13 \rightarrow \mathrm{H}-(14) ; \mathrm{H}-14 \rightarrow \mathrm{H}-(13) ; \mathrm{NHa} \rightarrow \mathrm{NHb} ; \mathrm{NHb} \rightarrow \mathrm{NHa} .{ }^{31} \mathrm{P}\left\{{ }^{1} \mathrm{H}\right\} \mathrm{NMR}$ 
(162.0 MHz, DMSO-d $\left.{ }_{6}\right) \delta(\mathrm{ppm}): 37.2$. Numbering of positions of AAM-DOPO shown in Table 2. HRMS (EI/FAB) $m / z$ : $[\mathrm{M}+\mathrm{H}]^{+}$calcd for $\mathrm{C}_{15} \mathrm{H}_{14} \mathrm{NO}_{3} \mathrm{P} 288.0784$; Found 288.0742.

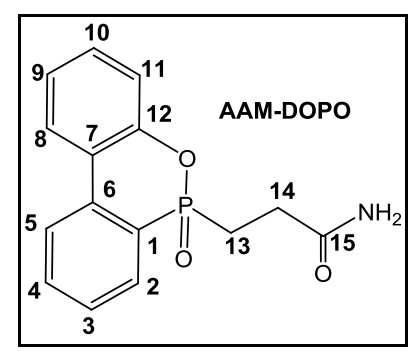

\subsection{Foam preparation}

A one-shot, free-rise method was used to prepare RPUR using a cast mold. Test samples with their coats removed were machined in accordance with the test standard. In this study, the molar ratio of $\mathrm{NCO}$ to $\mathrm{OH}$ was 1.1. The phosphorus content of the RPUF was fixed to $1 \mathrm{wt} \%$ and 2 wt $\%$ respectively.

Flame retardants TCPP, PLF140, ETA-DOPO, DTE-DOPO, AAM-DOPO were incorporated in RPUF production process. The FR additives were first mixed or dispersed in the polyol, and subsequently other ingredients of the foam formulation were added. The formulated polyol was then reacted with MDI and allowed for formation of free rise foams. The exact recipes of various foams are listed in Table 1. The FPUR-PIR foams with TCPP, PLF140, ETADOPO, DTE-DOPO and AAM-DOPO are abbreviated as RPUF/TCPP, RPUF/PLF140, RPUF/ETA-DOPO, RPUF/DTE-DOPO and RPUF/AAM-DOPO, respectively.

Table 1 Formulations of flame retardant RPUF composites.

\begin{tabular}{cccccccc}
\hline \multirow{2}{*}{ Sample } & \multicolumn{2}{c}{$\begin{array}{c}\text { Polyol } \\
(\mathrm{g})\end{array}$} & $\begin{array}{c}\text { MDI } \\
(\mathrm{g})\end{array}$ & $\begin{array}{c}\text { Catalyst } \\
(\mathrm{g})\end{array}$ & $\begin{array}{c}\text { Silicone surfactant } \\
(\mathrm{g})\end{array}$ & $\begin{array}{c}\text { Blowing agent } \\
(\mathrm{g})\end{array}$ \\
\cline { 2 - 8 } & RH360 & RN411 & M600 & Dibut. & Tri. & Tegostab 8460 & Cyclopentane \\
\hline RPUF & 50 & 50 & 102.5 & 0.6 & 0.8 & 3.0 & 10 \\
RPUF/TCPP & 50 & 50 & 102.5 & 0.6 & 0.8 & 3.0 & 10 \\
RPUF/PLF140 & 50 & 50 & 102.5 & 0.6 & 0.8 & 3.0 & 10 \\
RPUF/ETA-DOPO & 50 & 50 & 102.5 & 0.6 & 0.8 & 3.0 & 10 \\
RPUF/DTE-DOPO & 50 & 50 & 102.5 & 0.6 & 0.8 & 3.0 & 10 \\
RPUF/AAM-DOPO & 50 & 50 & 102.5 & 0.6 & 0.8 & 3.0 & 10 \\
\hline
\end{tabular}

\subsection{Characterization}

The apparent density of RPUF was measured according to ASTM D 1622-03 by determining the weight of cut foams. The dimension of specimens was $30 \times 30 \times 30 \mathrm{~mm}^{3}$. The apparent densities of five specimens per sample were measured, and the average values are reported. 
${ }^{1} \mathrm{H},{ }^{31} \mathrm{P}\left\{{ }^{1} \mathrm{H}\right\}$ and ${ }^{13} \mathrm{C}\left\{{ }^{1} \mathrm{H}\right\}$ NMR spectra were collected at ambient temperature using Bruker AV-III 400 spectrometer (Bruker Biospin AG, Fällanden, Switzerland). ${ }^{1} \mathrm{H}$ and ${ }^{13} \mathrm{C}$ chemical shifts $(\delta)$ in ppm were calibrated to residual solvent peaks. The ${ }^{31} \mathrm{P}$ chemical shifts were referenced to an external sample with neat $\mathrm{H}_{3} \mathrm{PO}_{4}$ at $0.0 \mathrm{ppm}$. High-resolution mass spectrometry (HR-MS) was performed by the MS-service of the Laboratory for Organic Chemistry at the ETH Zurich on a Waters Micromass AutoSpec-Ultima spectrometer (EI).

\% Phosphorus Analyses were carried out using the inductively coupled plasma optical emission spectrometry method (ICP-OES), on an Optima 3000(PerkinElmer AG, Rotkreuz, Switzerland) instrument. Sample preparation for ICP-OES consists of mixing of samples (300 mg) with $\mathrm{H}_{2} \mathrm{O}_{2}(1 \mathrm{~mL})$ and $\mathrm{HNO}_{3}(3 \mathrm{~mL})$ followed by digestion using a microwave.

The foams were evaluated for their flammability according to UL 94-HB test where the specimen is tested in a horizontal orientation. In this test the flame is applied to the end of specimen for $60 \mathrm{~s}$ and then removed, while a cotton web was placed underneath the test specimen. The dimension of specimens was $150 \times 50 \times 13 \mathrm{~mm}^{3}$.

Limiting Oxygen Index (LOI) values of all RPUF samples were measured on FTT oxygen index apparatus according to ASTM D2863-97. The dimension of specimens was $150 \times 10 \times 10$ $\mathrm{mm}^{3}$.

Cone calorimetry (CONE) tests were performed with an incident radiant flux of $35 \mathrm{~kW} \cdot \mathrm{m}^{-2}$, according to ISO 5660 protocol. The specimens $\left(100 \times 100 \times 30 \mathrm{~mm}^{3}\right)$ were measured horizontally without any grids. Parameters such as heat release rate (HRR), peak of heat release rate (PHRR), average specific extinction area (av-SEA), total smoke production (TSP), total smoke release (TSR), total heat release (THR) and the remaining residue were recorded.

Heat release rates (HRR) of samples were determined using pyrolysis combustion flow calorimeter (PCFC) (Fire Testing Technology Instrument UK) following ASTM D7309. Each sample ( 2 mg) was exposed to a heating rate of $1{ }^{\circ} \mathrm{C} \cdot \mathrm{s}^{-1}$ from 150 to $900{ }^{\circ} \mathrm{C}$ in the pyrolysis zone.

Thermogravimetric analysis (TGA) was performed on a NETZSCH TG 209 F1 instrument. Tests were conducted on 2-5 mg sample under nitrogen atmosphere (flow of $50 \mathrm{ml} / \mathrm{min}$ ) at a heating rate of $10^{\circ} \mathrm{C} / \mathrm{min}$ from 25 to $800^{\circ} \mathrm{C}$.

Pyrolysis-Gas Chromatography Mass Spectrometry (Py-GC-MS) measurements were performed by placing 30-100 $\mu \mathrm{g}$ of polymer in a quartz tube $(1 \mathrm{~mm}$ internal diameter $\times 25 \mathrm{~mm}$ length). The polymer was then loaded in the pyrolysis probe (5200 (CDS Analytical, Inc., Oxford, PA)) and placed in the special inlet at the interface. The polymer was pyrolyzed at 800 ${ }^{\circ} \mathrm{C}$ under helium atmosphere for $30 \mathrm{~s}$. The volatiles were separated by a Hewlett-Packard 5890 Series II gas chromatograph and analyzed by a Hewlett-Packard 5989 Series mass spectrometer.

The TG-FTIR-MS analysis was performed using Netzsch TG 209 F1 TGA instrument coupled with a FTIR (Bruker Tensor 27) and mass spectrometer (Netzsch QMS 403 C). 
About $10 \mathrm{mg}$ of the sample was heated under helium flow rate of $50 \mathrm{~mL} \mathrm{~min}^{-1}$ and a heating rate of $10{ }^{\circ} \mathrm{C} \mathrm{min}^{-1}$ from 30 to $900{ }^{\circ} \mathrm{C}$. The gas ionization was performed at $100 \mathrm{eV}$. The FTIR spectra were collected at a resolution of $4 \mathrm{~cm}^{-1}$, and 200 scans were co-added per spectrum.

The char layers after CONE test were observed via Scanning Electron Microscopy (SEM) and Energy Dispersive Spectrometer (EDX). The surface morphology of the samples was observed with an S-4800 (JEOL Japan) SEM with an accelerating voltage of $5 \mathrm{kV}$. The SEM instrument was integrated with an energy dispersive X-ray (EDX) microanalyser for elemental analysis.

\section{Results and Discussion}

\subsection{Combustion behavior}

\subsubsection{UL $94 \mathrm{HB}$ rating and LOI}

The structures of flame retardants, phosphorus content analysis of foams, UL 94-horizontal burning test results and LOI values of various RPUF formulations are summarized in Table 2. Unlike other flame retardant additives tested in this work, PLF140 is phosphorus containing polyol terminal groups which can react with the isocyanate and be an integral part of the polyurethane backbone. On the other hand, DOPO derivatives are composed of P-C, P-N and P$\mathrm{O}$ bonds depending on the linkers attached to the main phosphorus moiety as well as different terminal functional groups (amine and amide groups). DTE-DOPO flame retardant additive includes an inbuilt melamine structural unit. Melamine is very effective in rigid polyurethane foam and is widely used as a flame retardant [27]. The combination of DOPO compound with $\mathrm{N}$-containing substituents may enhance the flame retardant activity in both gas-phase and condensed-phase action due to possible synergism of phosphorus and nitrogen [24]. The average density of various RPUF formulations is about $52 \pm 4 \mathrm{~kg} \cdot \mathrm{m}^{-3}$. Element analysis by ICPOES shows the experimental phosphorus contents are exactly the same as the theoretical values. For foams containing all DOPO derivatives, we could achieve a classification of HF-1 and an increased LOI values from $19.3 \%$ up to $23.2 \%$ with 2 wt $\% \mathrm{P}$ in flame retarded RPUF. Flame retarded RPUF with 1 wt \% P can only achieve a UL 94 HB classification of HF-2 and thus further emphasis was given to RPUF with $2 \mathrm{wt} \% \mathrm{P}$ for other analysis.

\subsubsection{CONE test}

The cone calorimeter (CONE), based on the oxygen consumption principle, has been widely used to investigate the combustion behaviors of materials. Some important information such as heat release rate (HRR), total smoke release (TSR), CO production (COP), peak of heat release rate (PHRR), total heat release (THR), average specific extinction area (av-SEA), total smoke production (TSP) and residual mass are shown in Fig. 1 and presented in Table 3. These parameters are commonly used to evaluate the fire behaviors of polyurethane systems 
[28]. The HRR, especially the PHRR, usually represent the point in a fire where heat is likely to propagate further or ignite adjacent objects, so its reduction is important for fire safety. From Fig. 1, it can be observed that the incorporation of flame retardants in RPUF results in the decrease of HRR and increase of TSR and COP. The addition of flame retardants slow down the combustion of RPUF and prolong the burning time.

Table 2. Density and LOI of RPUF and RPUF with various flame retardants.

\begin{tabular}{|c|c|c|c|c|c|c|c|c|}
\hline \multirow[b]{2}{*}{ NO. } & \multirow[b]{2}{*}{ Sample } & \multirow[b]{2}{*}{$\begin{array}{c}\text { Flame retardant } \\
\text { structure }\end{array}$} & \multicolumn{3}{|c|}{$1 \% P$ in flame retardant RPUF } & \multicolumn{3}{|c|}{$2 \% \mathrm{P}$ in flame retardant RPUF } \\
\hline & & & $\begin{array}{c}\text { Element } \\
\text { analysis } \\
(\mathbf{P}, \%)\end{array}$ & $\begin{array}{c}\text { UL } 94 \\
\text { HB }\end{array}$ & LOI $(\%)$ & $\begin{array}{c}\text { Element } \\
\text { analysis } \\
(\mathrm{P}, \%)\end{array}$ & $\begin{array}{c}\text { UL } 94 \\
\text { HB }\end{array}$ & $\begin{array}{l}\text { LOI } \\
(\%)\end{array}$ \\
\hline 1 & RPUF & -- & -- & $\mathrm{HBF}$ & 19.3 & -- & $\mathrm{HBF}$ & 19.3 \\
\hline 2 & $\begin{array}{l}\text { RPUF/ } \\
\text { TCPP }\end{array}$ & & 0.98 & HF-2 & 21.5 & 2.01 & HF-1 & 23.2 \\
\hline 3 & $\begin{array}{c}\text { RPUF/ } \\
\text { PLF14 } \\
0\end{array}$ & & 1.02 & HF-2 & 20.8 & 1.97 & HF-1 & 22.2 \\
\hline 4 & $\begin{array}{l}\text { RPUF/ } \\
\text { ETA- } \\
\text { DOPO }\end{array}$ & & 0.96 & HF-2 & 20.8 & 2.04 & HF-1 & 22.2 \\
\hline 5 & $\begin{array}{c}\text { RPUF/ } \\
\text { DTE- } \\
\text { DOPO }\end{array}$ & & 1.00 & HF-2 & 20.9 & 1.99 & HF-1 & 22.3 \\
\hline 6 & $\begin{array}{l}\text { RPUF/ } \\
\text { AAM- } \\
\text { DOPO }\end{array}$ & & 0.99 & HF-2 & 20.5 & 2.01 & HF-1 & 22.2 \\
\hline
\end{tabular}

The RPUF/TCPP formulation has the lowest HRR and the highest THR and COP compared with other systems. RPUF with DTE-DOPO has lower TSP and COP as well as higher residue compared to other RPUF formulations used in this work. Among the halogen free flame retardant formulations, RPUF/PLF140 has the highest COP about $0.015 \mathrm{~g} / \mathrm{s}$ and similar to that of RPUF/TCPP. It can be inferred that the flame retardant mechanisms of DOPO based derivatives are different compared to PLF140 and TCPP. PLF140 acts in both the gas-phase and the condensed-phase as a reactive flame retardant. However, its activity in the condensed phase is weaker than that of DOPO derivatives, as interpreted from the increased char residue of PRUF/ETA-DOPO, RPUF/DTE-DOPO and RPUF/AAM-DOPO. TCPP is mainly active in the gas phase by producing $\mathrm{PO}$ and $\mathrm{Cl}$ radicals which interferes with the combustion process and reduces the flame energy of RPUF during combustion. Incomplete combustion due to catalytic recombination activity of $\mathrm{PO}$ and $\mathrm{Cl}$ radicals results in an increase in the smoke production [29]. However, based on the increase of char residue and lower TSP (Table 3) com- 
pared to RPUF/TCPP, we speculate that DOPO derivatives may have higher condensed phase activity compared to TCPP.
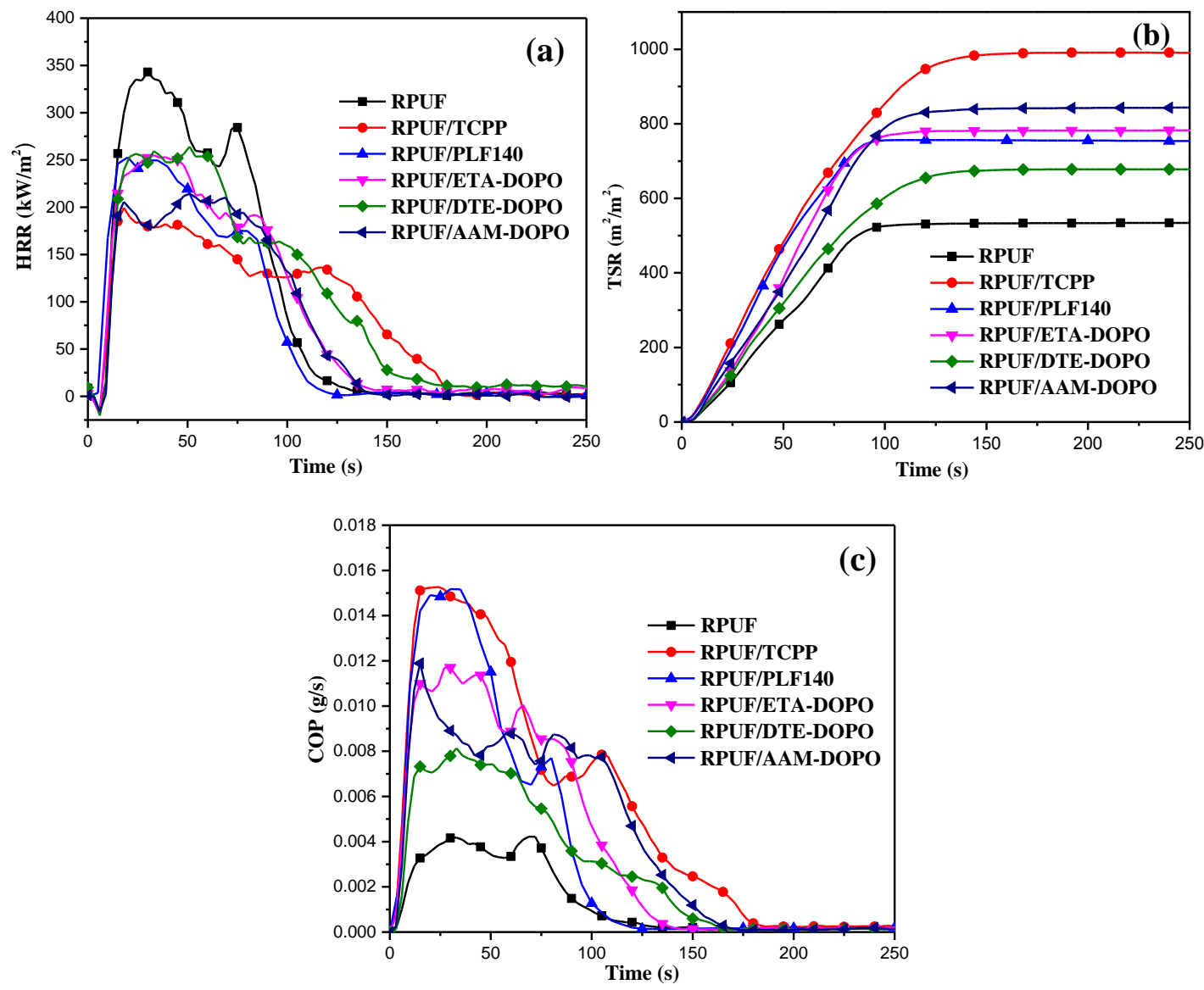

Fig. 1. HRR (a), TSR (b) and COP (c) curves of RPUF and flame retardant RPUF $\left(35 \mathrm{~kW} / \mathrm{m}^{2}\right)$.

Table 3. CONE calorimetric data of RPUF and flame retardant RPUF $\left(35 \mathrm{~kW} / \mathrm{m}^{2}\right)$.

\begin{tabular}{cccccc}
\hline Sample & $\begin{array}{c}\text { PHRR } \\
\left.\mathrm{kW} \cdot \mathrm{m}^{-2}\right)\end{array}$ & $\begin{array}{c}\text { THR } \\
\left(\mathrm{MJ} \cdot \mathrm{m}^{-2}\right)\end{array}$ & $\begin{array}{c}\text { av-SEA } \\
\left(\mathrm{m}^{2} \cdot \mathrm{kg}^{-1}\right)\end{array}$ & $\begin{array}{c}\text { TSP } \\
\left(\mathrm{m}^{2} \cdot \mathrm{kg}^{-1}\right)\end{array}$ & $\begin{array}{c}\text { Residual mass } \\
(\%)\end{array}$ \\
\hline RPUF & $343.0 \pm 11.9$ & $24.9 \pm 0.7$ & $506.4 \pm 12.5$ & $4.7 \pm 0.2$ & $23.0 \pm 0.8$ \\
RPUF/TCPP & $199.4 \pm 2.6$ & $21.8 \pm 0.2$ & $792.3 \pm 4.5$ & $9.8 \pm 0.1$ & $25.0 \pm 0.9$ \\
RPUF/PLF140 & $252.8 \pm 4.2$ & $18.8 \pm 0.4$ & $683.9 \pm 10.2$ & $6.5 \pm 0.3$ & $25.2 \pm 1.2$ \\
RPUF/ETA-DOPO & $255.1 \pm 3.5$ & $23.0 \pm 1.5$ & $737.5 \pm 8.3$ & $7.6 \pm 0.3$ & $27.9 \pm 0.5$ \\
RPUF/DTE-DOPO & $264.1 \pm 3.7$ & $23.1 \pm 0.4$ & $580.9 \pm 7.1$ & $6.0 \pm 0.1$ & $33.8 \pm 1.3$ \\
RPUF/AAM-DOPO & $214.2 \pm 7.6$ & $19.3 \pm 1.3$ & $781.2 \pm 6.0$ & $7.5 \pm 0.2$ & $31.4 \pm 1.6$ \\
\hline
\end{tabular}

\subsection{Thermal Decomposition}

\subsubsection{PCFC analysis}

A pyrolysis combustion flow calorimeter (PCFC) was used to determine flammability characteristics of RPUF on a milligram scale [30]. It is a useful instrument to determine the fuel content of the volatile thermal degradation products of a material and can also offer a valuable insight into the mode of action of the flame retardants. The dynamic flammability data of 
various RPUF samples detected by PCFC are shown in Fig. 2 and summarized in Table 4. The total heat release (THR), the heat release capacity (HRC) and the peak heat release rate (PHRR) of RPUF are significantly reduced upon addition of flame retardants. Furthermore, all the flame retardants alter the thermal decomposition profile of RPUF. Pure RPUF primarily decomposes in one step, but flame retarded RPUF has a multi-step decomposition process. As seen in Fig. 2, the incorporation of flame retardants leads to an earlier decomposition of RPUF. It can be attributed to the formation of acidic phosphorus species during the degradation of the flame retardants, which accelerates the decomposition of RPUF to occur at a lower temperature [29]. RPUF/TCPP has a small degradation peak at about $200{ }^{\circ} \mathrm{C}$, which is attributed to the degradation and volatilization of TCPP. The peaks between $250-400{ }^{\circ} \mathrm{C}$ are assigned to the degradation of main bonds on the polyurethane chains. The peaks centered between $400-500{ }^{\circ} \mathrm{C}$ could be attributed to the further degradation of char layer formed in the initial degradation stage. RPUF/DTE-DOPO has the lowest THR and highest residue. It is worthy to note that addition of DOPO derivatives to RPUF increases the residue from $11.1 \%$ up to $25.2 \%$.

As a general remark, the PCFC results do not entirely fit with the CONE results due to different sample size and test conditions. Unlike in the CONE experiments, the solid phase reactions and the gas phase combustion reactions are separated. Tests in PCFC involve pyrolysis of the sample in an inert atmosphere followed by a high temperature oxidation of volatile pyrolysis products. Thus the combustion of the specimen in PCFC test is complete relative to the CONE test. The char residue for the same specimen in the CONE test is higher than in the PCFC test. RPUF/DTE-DOPO exhibits the highest char residue in both CONE and PCFC experiments.

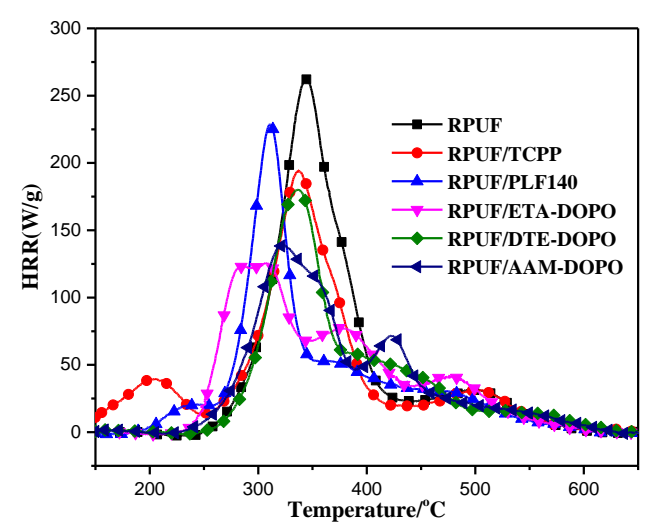

Fig. 2. HRR of RPUF and RPUF incorporated flame retardants from PCFC. 
Table 4. Detailed data of RPUF and RPUF incorporated flame retardants from PCFC.

\begin{tabular}{cccccc}
\hline Sample & THR $(\mathrm{KJ} / \mathrm{g})$ & HRC $(\mathrm{J} / \mathrm{g}-\mathrm{K})$ & PHRR $(\mathrm{W} / \mathrm{g})$ & $\mathrm{T}_{\max }$ & Residue $(\%)$ \\
\hline RPUF & 20.8 & 262 & 262.7 & 344.3 & 11.1 \\
RPUF/TCPP & 20.2 & 203 & 193.4 & 335.6 & 11.2 \\
RPUF/PLF140 & 17.5 & 231 & 228.7 & 311.0 & 19.0 \\
RPUF/ETA-DOPO & 18.2 & 125 & 121.7 & 280.2 & 22.1 \\
RPUF/DTE-DOPO & 16.8 & 182 & 179.7 & 334.9 & 25.2 \\
RPUF/AAM-DOPO & 17.1 & 140 & 139.2 & 320.6 & 21.8 \\
\hline
\end{tabular}

\subsubsection{TGA analysis}

Thermal behavior of the RPUFs under an inert atmosphere were investigated by TGA and DTG, the results are shown in Fig. 3 and summarized in Table 5. Pristine RPUF shows onestep mass loss in the temperature range of $250-400{ }^{\circ} \mathrm{C}$, while the flame retarded RPUF have two or more thermal decomposition stages. From the temperature of $10 \%$ mass loss $\left(\mathrm{T}_{10 \%}\right)$, it can be interpreted that all flame retardants advanced the initial decomposition of RPUF. The temperature at the first decomposition stage of RPUF/TCPP $\left(\sim 185^{\circ} \mathrm{C}\right)$ is lower than other systems. This is attributed to the low decomposition and volatilization temperature of TCPP [10]. RPUF/PLF140 also has a lower peak degradation temperature of around $230{ }^{\circ} \mathrm{C}$. However, for flame retarded RPUF with DOPO derivatives ETA-DOPO, DTE-DOPO and AAM-DOPO, the mass loss rate of the main decomposition step was decreased (Fig. 3(b)) from $10.5 \% \mathrm{~min}^{-1}$ to $6.3,8.7$ and $6.9 \% \mathrm{~min}^{-1}$, respectively. The char residue at $800{ }^{\circ} \mathrm{C}$ increased from $11.8 \%$ to $29.7 \%$, 30.2\% and $29.8 \%$ for ETA-DOPO, DTE-DOPO and AAM-DOPO formulations, respectively. This can be attributed to the presence of DOPO derivatives which can promote the char formation and decrease the main mass loss of RPUF during the main stage of thermal decomposition. The thermal degradation peaks of RPUF with DOPO derivatives at 350-450 ${ }^{\circ} \mathrm{C}$ are attributed to the further decomposition of char formed in the initial stage, which is consistent with the result of an earlier report [19]. RPUF/DTE-DOPO has the highest residue at $800{ }^{\circ} \mathrm{C}$, which is consistent with the CONE and PCFC results discussed earlier.
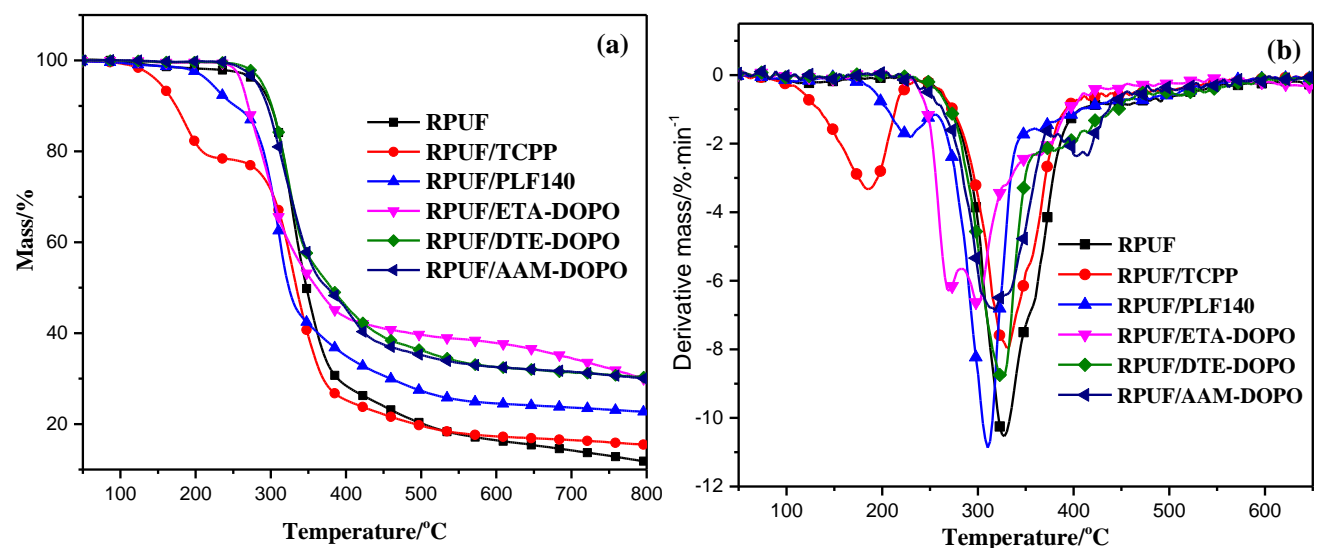

Fig. 3. TGA and DTG data of RPUF and RPUF incorporated flame retardants under nitrogen.

Table 5. Detailed TGA data of RPUF and RPUF incorporated flame retardants under nitrogen. 


\begin{tabular}{|c|c|c|c|c|c|c|}
\hline \multirow[b]{2}{*}{ Sample } & \multirow{2}{*}{$\begin{array}{l}\mathrm{T}_{10 \%} \\
\left({ }^{\circ} \mathrm{C}\right)\end{array}$} & \multicolumn{2}{|c|}{ Peak1 } & \multicolumn{2}{|c|}{ Peak2 } & \multirow{2}{*}{$\begin{array}{c}\text { Char Residue } \\
\text { at } 800^{\circ} \mathrm{C} \\
(\%)\end{array}$} \\
\hline & & $\begin{array}{c}\text { Temp } \\
\left({ }^{\circ} \mathrm{C}\right)\end{array}$ & $\begin{array}{c}\text { Mass loss rate } \\
\left(\% \cdot \min ^{-1}\right)\end{array}$ & $\begin{array}{l}\text { Temp } \\
\left({ }^{\circ} \mathrm{C}\right)\end{array}$ & $\begin{array}{c}\text { Mass loss rate } \\
\left(\% \cdot \min ^{-1}\right)\end{array}$ & \\
\hline RPUF & 300 & -- & -- & 327 & 10.5 & 11.8 \\
\hline RPUF/TCPP & 174 & 186 & 3.3 & 331 & 8.0 & 15.5 \\
\hline RPUF/PLF140 & 253 & 230 & 1.8 & 311 & 10.9 & 22.7 \\
\hline RPUF/ETA-DOPO & 270 & 269 & 6.3 & 301 & 6.7 & 29.7 \\
\hline RPUF/DTE-DOPO & 298 & 325 & 8.7 & 379 & 2.2 & 30.2 \\
\hline RPUF/AAM-DOPO & 296 & 318 & 6.9 & 404 & 2.4 & 29.8 \\
\hline
\end{tabular}

\subsection{Thermal decomposition mechanism}

Based on the interpretation of CONE and TGA data, RPUF/DTE-DOPO has a lower smoke production and shows excellent char formation compared to RPUF/PLF140 and other RPUF/DOPO based derivative formulations. To understand the difference in flame retardant performance of RPUF/TCPP and RPUF/DTE-DOPO compared to RPUF, additional investigations were carried out.

\subsubsection{Py-GC-MS analysis}

Py-GC-MS was employed to analyze the gaseous products formed during the thermal decomposition process of RPUF formulations. Py-GC-MS is an analytical method in which the test specimen is heated rapidly leading to fast pyrolysis of the polymer. The gaseous products thus formed are separated and analyzed by gas chromatography and mass spectroscopy. Fig. 4 shows the total ion chromatogram and Table 6 presents the evolved gaseous products of the RPUF, RPUF/TCPP and RPUF/DTE-DOPO were pyrolyzed at $800^{\circ} \mathrm{C}$. The decomposition of RPUF leads to formation of phenylisocyanate (retention time: $\mathrm{Rt}=3.388 \mathrm{~min}$ ), aniline $(\mathrm{Rt}=$ $3.565 \mathrm{~min}), 2$-(2-Hydroxypropoxy)-1-propanol $(\mathrm{Rt}=3.969 \mathrm{~min}), \mathrm{p}$-Tolyl isocyanate $(\mathrm{Rt}=$ $4.113 \mathrm{~min}), 3$-Hydroxy-3-methylbutanoic acid methyl ester $(\mathrm{Rt}=4.743 \mathrm{~min})$. These products correspond to the degradation of polyurethane chain [31].

In addition to these decomposition products, some products such as benzonitrile $(\mathrm{Rt}=4.352$ $\mathrm{min})$, biphenyl $(\mathrm{Rt}=5.980 \mathrm{~min})$ and dibenzofuran $(\mathrm{Rt}=6.718 \mathrm{~min})$ were also detected from the thermal decomposition of RPUF/DTE-DOPO formulas. Formation of these decomposition products is attributed to the chemical composition of DTE-DOPO which contains aromatic rings in its molecular structure. The decomposition products are consistent with earlier reports investigating the decomposition of DOPO based flame retardants [9,30]. Some phosphorusbased gaseous products were released from RPUF/TCPP. Unlike RPUF/TCPP, no phosphorus gaseous products could be detected for RPUF/DTE-DOPO. It is thus interpreted that DTEDOPO has a different flame inhibition activity compared to TCPP. TCPP is active primarily in the gas phase, whereas DTE-DOPO is active in both the condensed and the gas phase. DTE-DOPO released free radicals with quenching effects during thermal decomposition exert 
flame retardant effects in the gaseous phase [30,32]. But most fragments are kept in the condensed phase to form a char layer, thereby exerting a stronger flame retardant effect in the condensed phase.

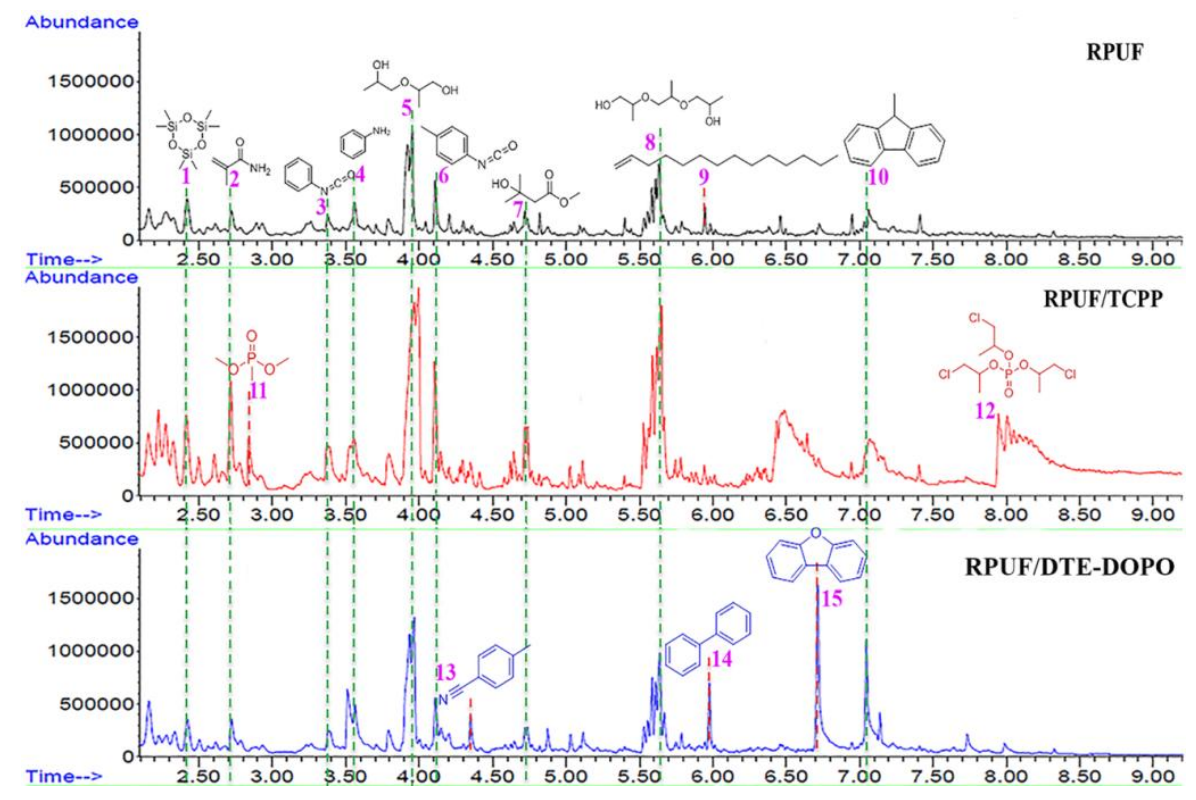

Fig. 4. Py-GC-MS chromatogram of the RPUF, RPUF/DTE-DOPO and RPUF/TCPP at $800{ }^{\circ} \mathrm{C}$.

Table 6. Pyrolysis products of RPUF, RPUF/TCPP and RPUF/DTE-DOPO.

\begin{tabular}{|c|c|c|c|c|c|c|c|}
\hline NO. & $\mathbf{m} / \mathbf{z}$ & Name & CAS & NO. & $\mathbf{m} / \mathbf{z}$ & Name & CAS \\
\hline 1 & 207 & Hexamethylcyclotrisiloxane & $541-05-9$ & 9 & 41 & 1-Tetradecene & $1120-36-1$ \\
\hline 2 & 41,85 & Methacrylamide & $79-39-0$ & 10 & 165 & 9-Methylfluorene & $2523-37-7$ \\
\hline 3 & 119 & Phenylisocyanate & $103-71-9$ & 11 & 94 & Dimethyl methylphosphonate & $756-79-6$ \\
\hline 4 & 93 & Aniline & $62-53-3$ & 12 & 99 & 2-propanol, 1-chloro-, phosphate & $13647-84-5$ \\
\hline 5 & 59 & $\begin{array}{l}\text { 2-(2-Hydroxypropoxy)-1- } \\
\text { propanol }\end{array}$ & $106-62-7$ & 13 & 117 & Benzonitrile & $104-85-8$ \\
\hline 6 & 133 & p-Tolyl isocyanate & $622-58-2$ & 14 & 154 & Biphenyl & $92-52-4$ \\
\hline 7 & 41 & $\begin{array}{l}\text { 3-Hydroxy-3- } \\
\text { methylbutanoic acid methyl } \\
\text { ester }\end{array}$ & $6149-45-7$ & 15 & 168 & Dibenzofuran & $132-64-9$ \\
\hline 8 & 59 & Tripropylene Glycol & $1638-16-0$ & & & & \\
\hline
\end{tabular}

\subsubsection{Infrared spectroscopy analysis of the evolved gases}

In order to track the gaseous products as a function of temperature and to understand the thermal decomposition mechanism, a thermogravimetric analysis coupled with infrared spectrometry (TG-FTIR) was performed. A time profile of gas generation can provide an insight into the variation of the gas composition with respect to decomposition temperature. As illu- 
strated in Fig. 5, we could conclude that the absorption strength of different gaseous components change with the increasing temperature. At $155^{\circ} \mathrm{C}$, the peak at $2968 \mathrm{~cm}^{-1}$ is referred to evolution of the blowing agent cyclopentane. At $320^{\circ} \mathrm{C}$, the obvious peak at $1000-1100 \mathrm{~cm}^{-1}$ seen in RPUF/DTE-DOPO can be attributed to the absorbance of aromatic compounds (1046 $\mathrm{cm}^{-1}$ ) $[13,33]$. The decomposition of DTE-DOPO advances the release of aromatic compounds. The hydrocarbon $\left(2960 \mathrm{~cm}^{-1}\right)$ release for RPUF/TCPP and RPUF/DTE-DOPO systems occurs at a lower temperature compared to the pure RPUF [34-36]. This indicates that the investigated phosphorus-based flame retardants accelerate the decomposition of RPUF. This can be attributed to the formation of phosphoric acid due to the decomposition of flame retardants [29].
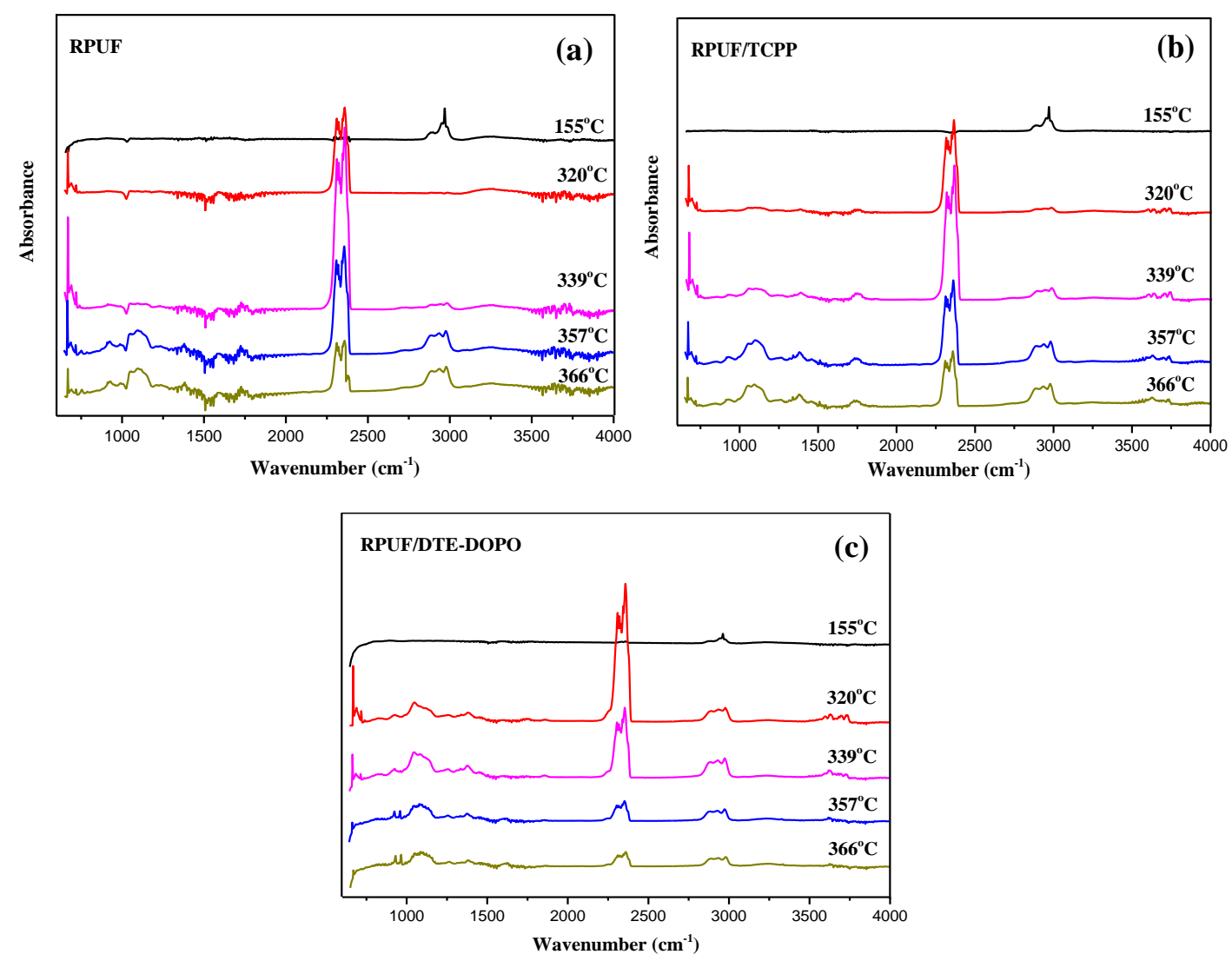

Fig. 5. FTIR spectra of (a) RPUF, (b) RPUF/TCPP, (c) RPUF/DTE-DOPO evolved gases at different temperature in helium.

For further understanding the effects of flame retardant additives on evolved gases, the relation between relative intensity of characteristic peaks corresponding to gases like $\mathrm{CO}_{2}$, - $\mathrm{NCO}$ compounds, aromatic compounds, hydrocarbons and $\mathrm{HCN}$ as a function of temperature are shown in Fig. 6. It can be seen that flame retardants decrease the release of $\mathrm{CO}_{2}\left(2356 \mathrm{~cm}^{-1}\right)$, NCO containing substances $\left(1710 \mathrm{~cm}^{-1}\right)$, aromatic compounds $\left(669 \mathrm{~cm}^{-1}\right)$ hydrocarbons $(2960$ $\left.\mathrm{cm}^{-1}\right)$ and $\mathrm{HCN}\left(710 \mathrm{~cm}^{-1}\right)$ [34-36]. RPUF/DTE-DOPO produces the highest amount of $\mathrm{CO}_{2}$ and aromatic compounds compared to the RPUF/TCPP system. Compared to virgin RPUF, RPUF/DTE-DOPO foams showed a decreased release of toxic -NCO containing products, $\mathrm{HCN}$ and hydrocarbons. This could be due to reactivity of the amino group of DTE-DOPO towards the - $\mathrm{NCO}$ groups at higher temperatures, thereby reducing the - NCO containing 
products and HCN [27]. DTE-DOPO can reduce the release of smoke and toxic gases by keeping decomposition fragments in the condensed phase, thereby enhancing the char residue.
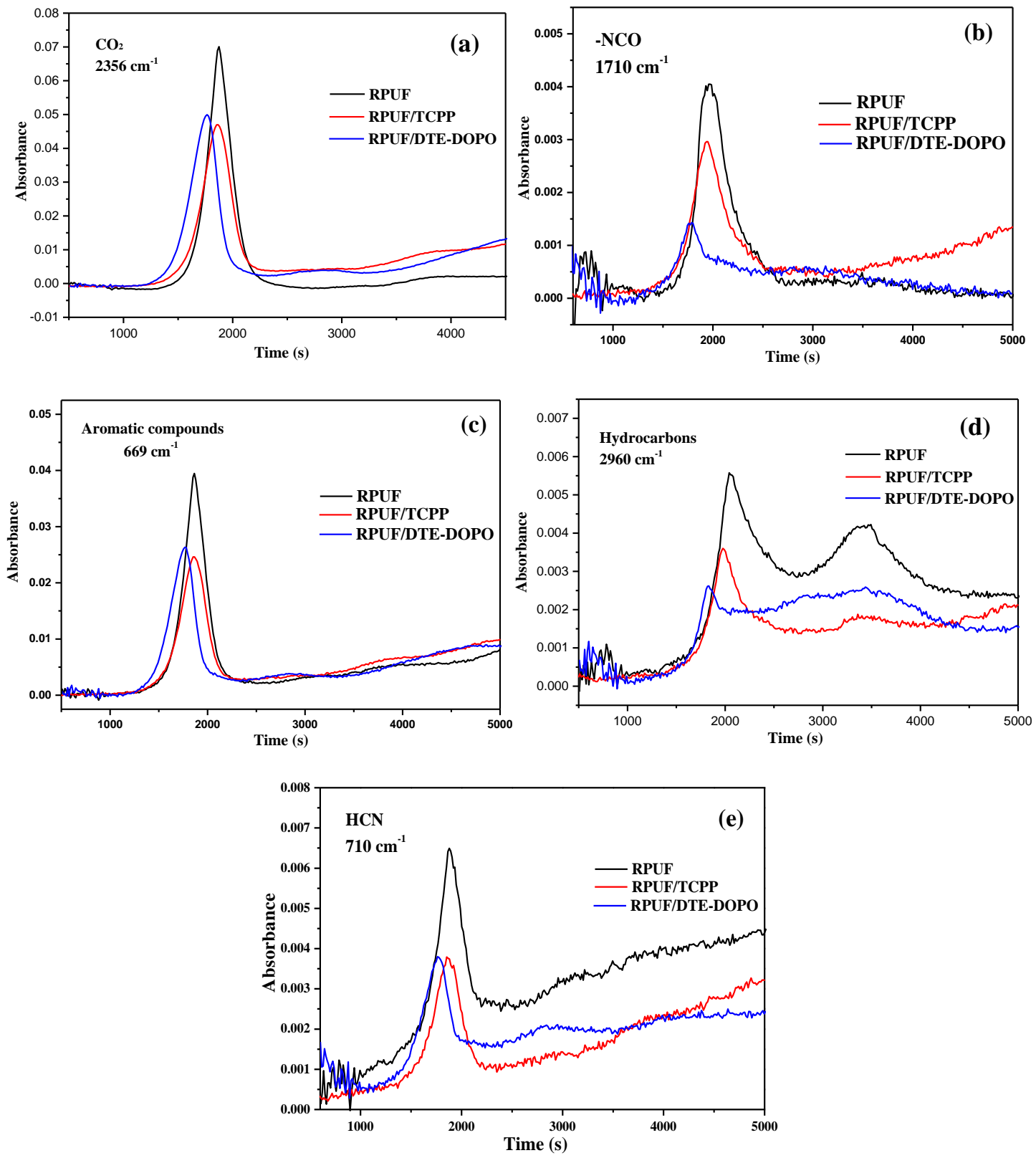

Fig. 6. Comparison of TG-FTIR spectra of pyrolysis products for RPUF, RPUF/TCPP and RPUF/DTE-DOPO.

\subsubsection{TG-MS measurements}

The evolved gaseous products formed during the thermal decomposition of RPUF, RPUF/TCPP and RPUF/DTE-DOPO were determined by thermogravimetry coupled to a mass spectrometer (TG-MS). The intensity curves of water $(\mathrm{m} / \mathrm{z} 18)$, amines $(\mathrm{m} / \mathrm{z} 30)$, cyanic acid $(\mathrm{m} / \mathrm{z}, 43)$ and C-4 butylene $(\mathrm{m} / \mathrm{z}, 56)$ release as function of time are shown in Fig. 7 [37,38]. It can be seen RPUF/DTE-DOPO decomposes earlier than RPUF and RPUF/TCPP. It may be attributed to the catalysis of acidic phosphorus-based products formed from the decomposition of DTE-DOPO and their ability to stay in the condensed phase compared to the more volatile TCPP. Considering equal sample mass in the TGA experiments, RPUF/DTE- 
DOPO has the lowest intensity of release of water, amines, cyanic acid and C-4 butylene. It is known that, the cyanic acid is toxic and can cause lung injury, and C-4 butylene is the precursor of smoke [27]. It means that DTE-DOPO lowers the smoke and toxicity release in the gas phase, which is consistent with the results of combustion test and TG-FTIR test. It is probably induced by the melamine component of DTE-DOPO which can react with the decomposition products containing - NCO groups [27]. Because the intensity of - $\mathrm{NCO}$ compounds and $\mathrm{HCN}$ depend on the mass of isocyanate used in manufacturing the foams, the intensity peak area per unit mass of -NCO, HCN from TG-FTIR and HNCO from TG-MS of RPUF, RPUF/TCPP and RPUF/DTE-DOPO were calculated by Origin 8.5, and the ratio between RPUF/TCPP, RPUF/DTE-DOPO and RPUF are presented in Table 7. It can be seen that RPUF/DTEDOPO exhibited a significant decrease in the production of $-\mathrm{NCO}$ containing products and HCN compared to RPUF/TCPP. DTE-DOPO not only contributes in the gas phase but also in the condensed phase and keeps more phosphorus in char which facilities the formation of a compact and thermally stable char layer.
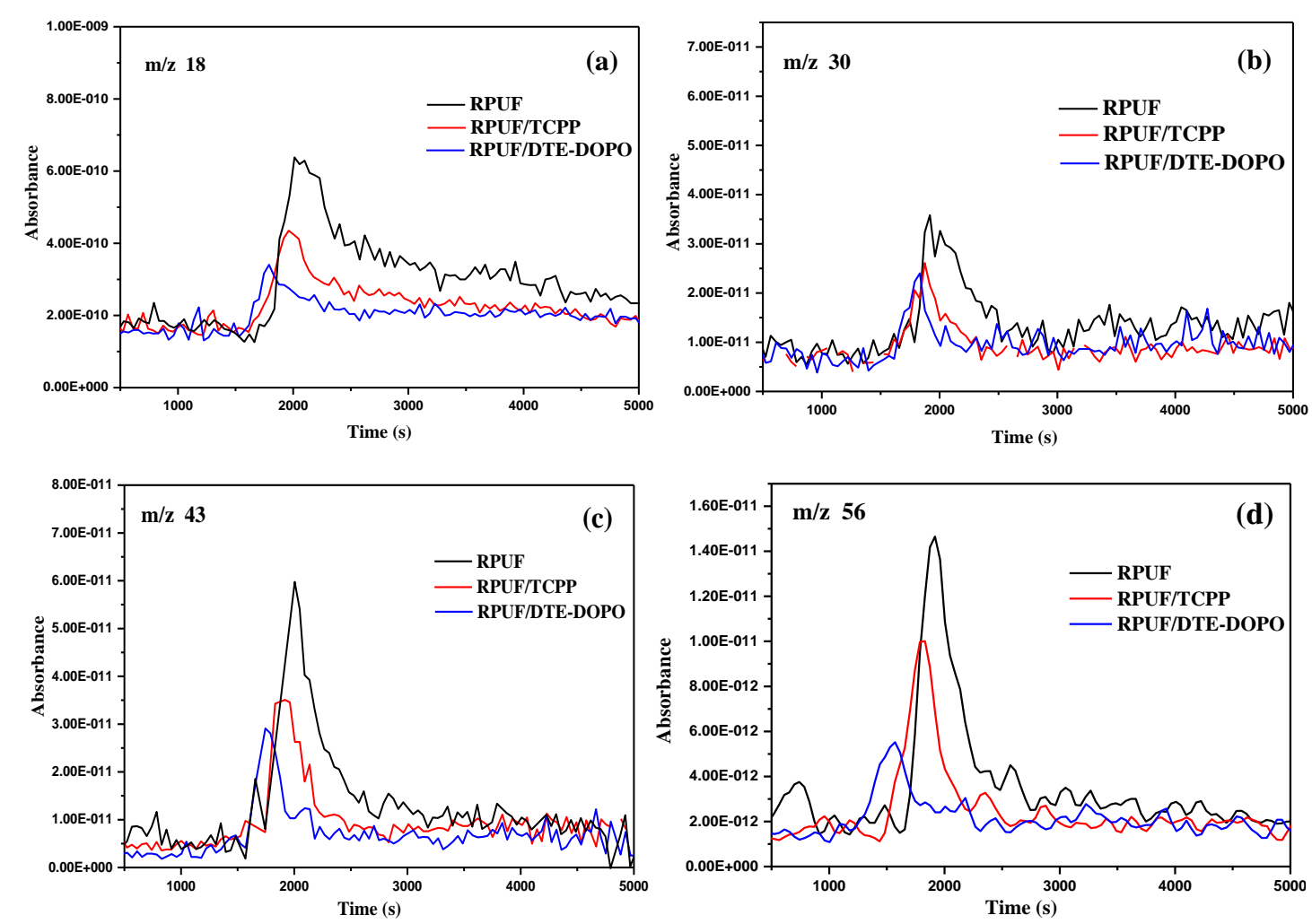

Fig. 7. Comparison of TG-MS spectra of pyrolysis products for RPUF, RPUF/TCPP and RPUF/DTE-DOPO.

Table 7. Ratio of peaks area per unit mass between RPUF/TCPP, RPUF/DTE-DOPO and RPUF.

\begin{tabular}{ccc}
\hline Evolved products & RPUF/TCPP : RPUF (\%) & RPUF/DTE-DOPO : RPUR (\%) \\
\hline -NCO & $95.3 \pm 2.1$ & $44.8 \pm 2.7$ \\
HCN & $60.5 \pm 1.6$ & $50.7 \pm 1.4$
\end{tabular}




\subsection{Morphology and chemical analyses of residues}

\subsubsection{SEM analysis of residues after CONE test}

To further understand the condensed phase activity of the flame retardants, we have characterized the residues of RPUFs after the CONE test using SEM. SEM images of the residues are presented in Fig. 8. As shown in Fig. 8, the char of pure RPUF showed a loose structure, and a lot of holes on the surface, which indicates inefficient barrier protection for underlying layers. Compared to the char of virgin RPUF, RPUF/TCPP (Fig. 8(b)) and RPUF/PLF140 (Fig. 8(c)) have spherical structures on the surface and are coherent, but still have some cracks on the surface. However, the char layer for RPUF with DOPO based derivatives are distinct compared to the earlier discussed systems. Especially noticeable is the char structure of RPUF/DTE-DOPO: it is very continuous and compact, and without any cracks and holes on the surface. The result was consistent with the previous analysis in that the formation of a thermally stable char layer increases the flame retardancy of RPUF.
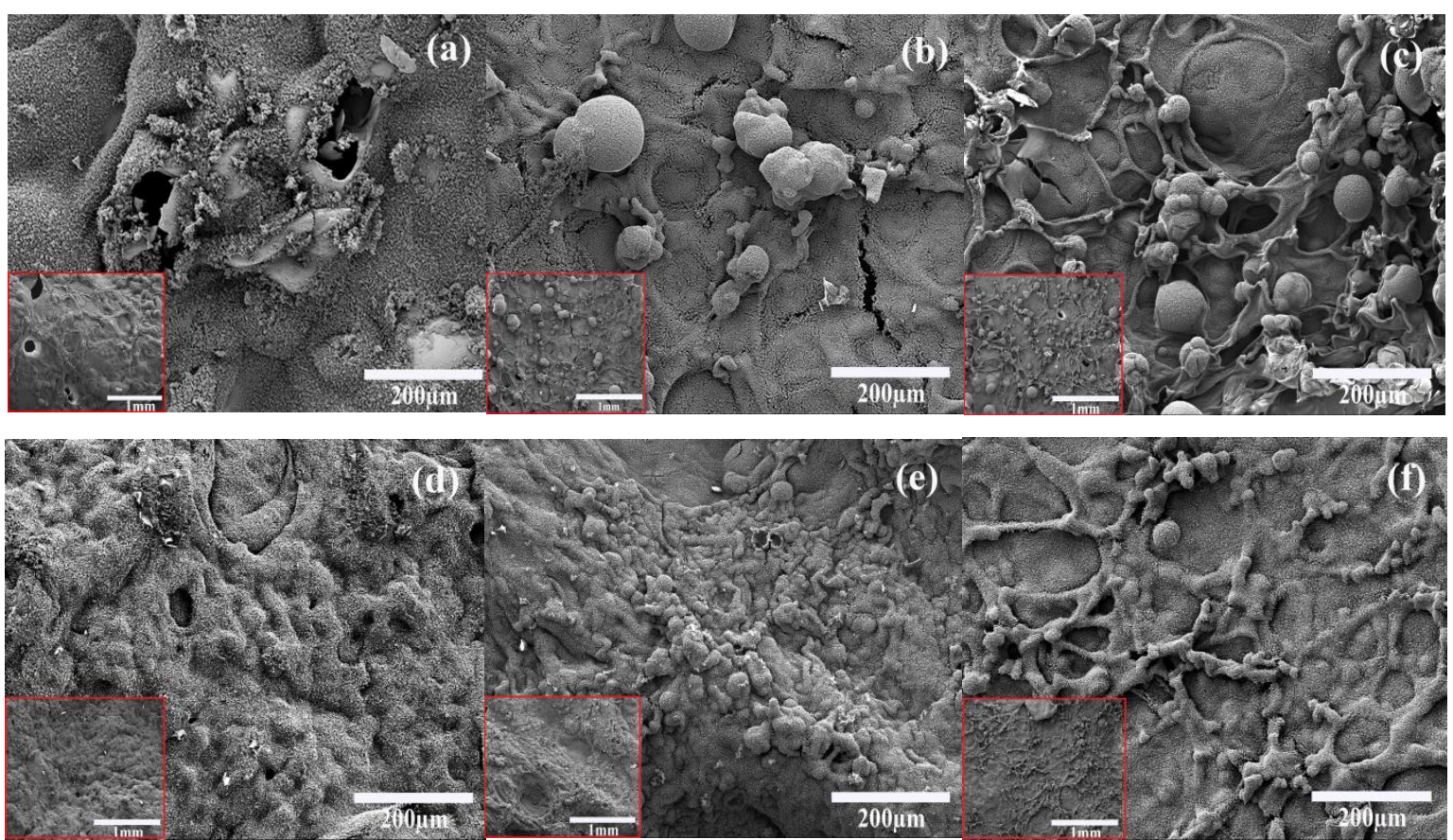

Fig. 8. SEM images of the char residues with different magnification times (a) RPUF, (b) RPUF/TCPP, (c) RPUF/PLF-140, (d) RPUF/ETA-DOPO, (e) RPUF/DTE-DOPO and (f) RPUF/AAM-DOPO.

\subsubsection{Elemental analysis of residual chars after cone calorimeter test}

EDX was also used to characterize the elements presented on the surface and understand its surface chemistry. RPUF, RPUF/TCPP and RPUF/DTE-DOPO were chosen for the elemental analysis. The residue of every specimen was grinded sufficiently before the EDX test to ensure elemental homogeneity. The data are shown in Fig. 9 and presented in the Table 8. For all the systems, the main composition of the residue was carbon. Char layer of RPUF/DTEDOPO has higher phosphorus content (approximately 3.7\%) than RPUF/TCPP (approximate- 
ly $2.0 \%$ ) The C/P ratio of RPUF/TCPP at approximately 36.6 is higher than RPUF/DTEDOPO (approximately 21.6). It can be deduced that DTE-DOPO had strong activity in the condensed phase, which can decompose to form phosphorus containing fragments and crosslink to facilitate the formation of compact and continuous char layer. In the case of TCPP, the mechanism is significantly different: it is mainly active in the gas phase and releases a lot of phosphorus compounds which facilitates recombination of fuel relevant radicals in the primary stage of combustion.

Table 8. Element contents from EDX analysis.

\begin{tabular}{cccccc}
\hline Sample & $\mathbf{C}(\boldsymbol{\%})$ & $\mathbf{N}(\boldsymbol{\%})$ & $\mathbf{O}(\boldsymbol{\%})$ & $\mathbf{P}(\boldsymbol{\%})$ & $\mathbf{C} / \mathbf{P}$ \\
\hline RPUF & 73.7 & 7.5 & 18.8 & -- & -- \\
RPUF/TCPP & 73.8 & 8.2 & 16.0 & 2.0 & 36.9 \\
RPUF/DTE-DOPO & 80.9 & 5.7 & 9.7 & 3.7 & 21.9 \\
\hline
\end{tabular}

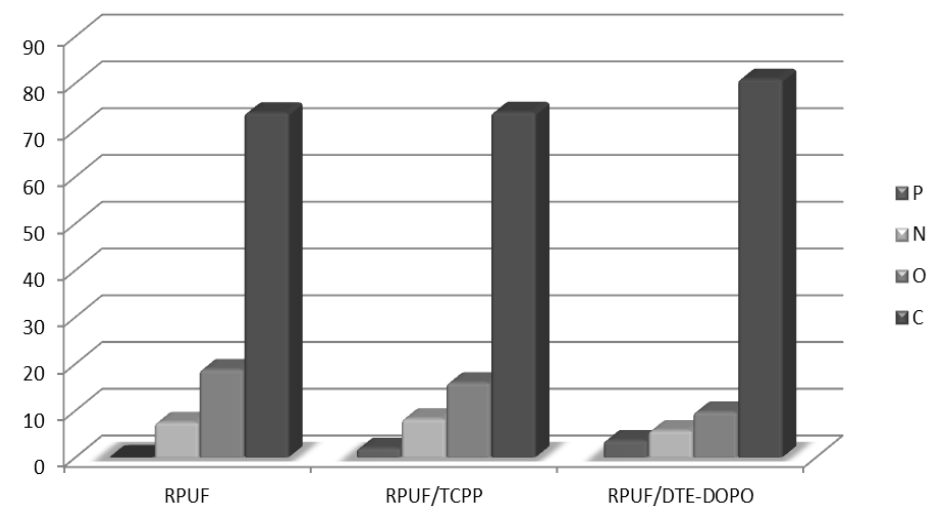

Fig. 9. Elemental analysis of the residues for the samples.

\section{Conclusions}

In this work, the DOPO based derivatives ETA-DOPO, DTE-DOPO and AAM-DOPO have been successfully synthesized and then incorporated into RPUF. The flame retardant performances of DOPO based derivatives were compared with traditional flame retardant TCPP and reactive flame retardant PLF140. The results indicate that with the addition of 2 wt $\%$ phosphorus in RPUF, it is possible to decrease the peak of the heat release rate from 343 to 200$264 \mathrm{~kW} \cdot \mathrm{m}^{-2}$. DOPO based derivatives not only have a lower production of smoke and toxicity than TCPP and PLF140 but also an increase in the char residue value of RPUF by more than $11 \%$. CONE tests show that DTE-DOPO has lower smoke and toxicity production and excellent performance in char formation compared with other flame retardants. Gaseous products were evaluated by Py-GC-MS and TG-FTIR-MS, showing DTE-DOPO reduced the production of-NCO containing products, $\mathrm{HCN}$, hydrocarbons, amines and cyanic acid in the gas phase. It is probably induced by the melamine component of DTE-DOPO which can react with the $-\mathrm{NCO}$ groups and has smoke and toxicity suppression action during combustion. Meanwhile, the addition of DTE-DOPO revealed compact and tough residue structures, lead- 
ing to a stronger barrier effect in the condensed phase. Flame retardant mechanisms have been described in this work. Unlike TCPP, DTE-DOPO is not only active in the gas phase but also has a strong activity in the condensed phase, enabling the retention of more phosphorus and decomposition fragments, thereby decreasing the smoke production and toxicity.

\section{Acknowledgements}

This work was funded by China Scholarship Council, National Key Research and Development Plan of China (No. 2016YFB0302104). The NMR hardware used for measurements in this work was partially granted by the Swiss National Science Foundation (SNFS, grant no. 150638). The authors wish to thank Mr. Braid MacRae for his assistance in proof-reading of the manuscript.

\section{References}

[1] F.F. Feng and L.J. Qian, Polymer Composites, 35, (2014) 301.

[2] E. Ciecierska, M. Jurczyk-Kowalska, P. Bazarnik, M. Kowalski, S. Krauze and M. Lewandowska, Journal of Thermal Analysis and Calorimetry, 123, (2016) 283.

[3] F.B. Luo, K. Wu, Y.W. Li, J. Zheng, H.L. Guo and M.G. Lu, Journal of Applied Polymer Science, 132, (2015) 9.

[4] R. Yang, W. Hu, L. Xu, Y. Song and J. Li, Polymer Degradation and Stability, 122, (2015) 102.

[5] X. Liu, J. Hao and S. Gaan, RSC Advances, 6, (2016) 74742.

[6] L.L. Jiao, H.H. Xiao, Q.S. Wang and J.H. Sun, Polymer Degradation and Stability, 98, (2013) 2687.

[7] W. Zatorski, Z.K. Brzozowski and A. Kolbrecki, Polymer Degradation and Stability, 93, (2008) 2071.

[8] Final Draft prEN 13501-1: Fire classification of construction products and building elements. Part 1: classification using test data from reaction to fire tests., 2007.

[9] S. Gaan, S.Y. Liang, H. Mispreuve, H. Perler, R. Naescher and M. Neisius, Polymer Degradation and Stability, 113, (2015) 180.

[10] I. van der Veen and J. de Boer, Chemosphere, 88, (2012) 1119.

[11] H.M. Stapleton, S. Klosterhaus, A. Keller, P.L. Ferguson, S. van Bergen, E. Cooper, T.F. Webster and A. Blum, Environmental Science \& Technology, 45, (2011) 5323.

[12] H.M. Stapleton, S. Klosterhaus, S. Eagle, J. Fuh, J.D. Meeker, A. Blum and T.F. Webster, Environmental Science \& Technology, 43, (2009) 7490.

[13] X. Liu, Y. Zhou, J.W. Hao and J.X. Du, Journal of Applied Polymer Science, 132, (2015) 41846.

[14] X. Wang, Y. Hu, L. Song, H. Yang, W. Xing and H. Lu, Progress in Organic Coatings, 71, (2011) 72.

[15] K.A. Salmeia and S. Gaan, Polymer Degradation and Stability, 113, (2015) 119.

[16] M. Zhang, Z. Luo, J. Zhang, S. Chen and Y. Zhou, Polymer Degradation and Stability, 120, (2015) 427.

[17] M. Ciesielski, A. Schäfer and M. Döring, Polymers for Advanced Technologies, 19, (2008) 507.

[18] M. Rakotomalala, S. Wagner and M. Doring, Materials, 3, (2010) 4300.

[19] A. Konig and E. Kroke, Polymers for Advanced Technologies, 22, (2011) 5. 
[20] C. Hirsch, B. Striegl, S. Mathes, C. Adlhart, M. Edelmann, E. Bono, S. Gaan, K.A. Salmeia, L. Hoelting, A. Krebs, J. Nyffeler, R. Pape, A. Bürkle, M. Leist, P. Wick and S. Schildknecht, Archives of Toxicology, (2016) 1.

[21] P. Wang, F. Yang, L. Li and Z. Cai, Journal of Applied Polymer Science, 133, (2016) 43953.

[22] S. Huo, J. Wang, S. Yang, J. Wang, B. Zhang, B. Zhang, X. Chen and Y. Tang, Polymer Degradation and Stability, 131, (2016) 106.

[23] S. Gaan, M. Neisius, O. Cuchere, S. Liang and H. Mispreuve, Flame retardant polyurethanes based on novel phosphonamidate additives, at: Fire Safety Science, 821.

[24] M. Zhang, Z.Y. Luo, J.W. Zhang, S.G. Chen and Y.H. Zhou, Polymer Degradation and Stability, 120, (2015) 427.

[25] I. Butnaru, M. Fernández-Ronco, J. Czech-Polak, M. Heneczkowski, M. Bruma and S. Gaan, Polymers, 7, (2015) 1469.

[26] S. Gaan, M. Neisius, P. Mercoli, S. Liang, H. Mispreuve and R. Naescher, in, EMPA Eidgenoessische Materialpruefungs- und Forschungsanstalt, Switz.; Fritz Nauer AG . 2013, p. $52 \mathrm{pp}$.

[27] Q.W. Xu, H.M. Zhai and G.J. Wang, Fire and Materials, 39, (2015) 271.

[28] B. Wang, X. Wang, Y. Shi, G. Tang, Q. Tang, L. Song and Y. Hu, Radiation Physics and Chemistry, 81, (2012) 308.

[29] H. Singh and A.K. Jain, Journal of Applied Polymer Science, 111, (2009) 1115.

[30] K.A. Salmeia, J. Fage, S.Y. Liang and S. Gaan, Polymers, 7, (2015) 504.

[31] Y. Zhang, Z. Xia, H. Huang and H. Chen, Polymer Testing, 28, (2009) 264.

[32] S. Yang, J. Wang, S. Huo, M. Wang, J. Wang and B. Zhang, Polymer Degradation and Stability, 128, (2016) 89.

[33] X. Liu, D.M. Xu, Y.L. Wang, Y. Zhou and J.W. Hao, Journal of Thermal Analysis and Calorimetry, (2016) 1.

[34] A. Lorenzetti, M. Modesti, S. Besco, D. Hrelja and S. Donadi, Polymer Degradation and Stability, 96, (2011) 1455.

[35] Z. Bai, L. Song, Y. Hu and R.K.K. Yuen, Industrial and Engineering Chemistry Research, 52, (2013) 12855.

[36] X.L. Chen, L.L. Huo, C.M. Jiao and S.X. Li, Journal of Analytical and Applied Pyrolysis, 100, (2013) 186.

[37] H.F. Cheng, Q.F. Liu, J. Liu, B. Sun, Y.X. Kang and R.L. Frost, Journal of Thermal Analysis and Calorimetry, 116, (2014) 195.

[38] J. Bozi, M.R. Mihalyi and M. Blazso, Journal of Analytical and Applied Pyrolysis, 101, (2013) 103. 